Fanum

Forum Sociológico

Sociológico

Série II

26 | 2015

Número 26

\title{
A mobilidade e o lazer na constituição do espaço público contemporâneo : os protestos de $2013 \mathrm{em}$ São Paulo
}

Vitor Sorano Pereira

\section{(2) OpenEdition \\ Journals}

Edição electrónica

URL: https://journals.openedition.org/sociologico/1209

DOI: 10.4000/sociologico.1209

ISSN: 2182-7427

Editora

CICS.NOVA - Centro Interdisciplinar de Ciências Sociais da Universidade Nova de Lisboa

Edição impressa

Data de publição: 12 dezembro 2015

Paginação: 53-61

ISSN: 0872-8380

Refêrencia eletrónica

Vitor Sorano Pereira, «A mobilidade e o lazer na constituição do espaço público contemporâneo : os protestos de 2013 em São Paulo», Forum Sociológico [Online], 26 | 2015, posto online no dia 04 abril 2016, consultado o 29 março 2022. URL: http://journals.openedition.org/sociologico/1209 ; DOI: https://doi.org/10.4000/sociologico.1209 


\title{
A MOBILIDADE E O LAZER NA CONSTITUIÇÃO DO ESPAÇO PÚBLICO CONTEMPORÂNEO: OS PROTESTOS DE 2013 EM SÃO PAULO ${ }^{1}$
}

\author{
Vitor Sorano Pereira \\ Universidade Nova de Lisboa, Centro Interdisciplinar de Ciências Sociais (CICS-NOVA)
}

\begin{abstract}
Resumo
Os protestos de junho de 2013 em São Paulo puseram uma expressão massiva de dissenso em espaços urbanos da maior cidade do Brasil. O presente artigo argumenta que a mobilidade e o lazer foram centrais na constituição desse fenômeno, uma vez que foram constituintes das políticas-alvo dos protestos, das organizações que os convocaram e da dinâmica dos atos realizados nas ruas. O objetivo é mostrar como o espaço público contemporâneo é condicionado pela mobilidade e pelo lazer.
\end{abstract}

Palavras-chave: mobilidade; lazer; espaço público; protestos

\begin{abstract}
Protests held in June 2013 in São Paulo put a massive expression of dissent in urban spaces of Brazil's biggest city. This article argues that mobility and leisure were central to the constitution of this phenomenon, since both were constituents of the policies against which the protests were held, of the organizations that called the protests and of the dynamic of the protests on the streets. The objective is to show how contemporary public space is conditioned by mobility and leisure.
\end{abstract}

Keywords: mobility; leisure; public space; protests

\section{Introdução}

Em junho de 2013, ruas e praças de São Paulo foram tomadas por protestos que, à semelhança do observado a partir de 2010 em outras partes do mundo, romperam a ordem cotidiana da maior cidade brasileira ao preencher os espaços urbanos com expressões massivas de dissenso. $O$ objetivo do presente artigo é demonstrar que o lazer e a mobilidade, centrais às políticas urbanísticas atuais, caracterizam também essas manifestações e, portanto, devem ser pensados como condicionantes do espaço público contemporâneo.

A análise é feita em três etapas. Primeiro, olhamos dois dos alvos dos protestos: a realização no Brasil da Copa do Mundo de 2014 e da Copa das Confederações de 2013, voltada a promover a atratividade turística das cidades brasileiras e justificada pelos impactos positivos na infraestrutura de trânsito e transporte; e a cobrança e o aumento da tarifa no transporte coletivo público em São Paulo, que, como iremos desenvolver, atrelam a capacidade de deslocamento do indivíduo a seu capital financeiro.

Na sequência, debruçamo-nos sobre duas organizações que convocaram os protestos, e demonstramos como a crítica à desigualdade, apontada na literatura como principal força motriz do atual ciclo de mobilizações, em São Paulo toma a forma de questionamento aos impactos da promoção da mobilidade e do lazer por meio da Copa, e de revindicação ao direito ao deslocar-se e, em menor escala, ao divertir-se.

Terminamos, na terceira etapa, com a exploração dos dados sobre a dinâmica, nas ruas, de 14 protestos realizados entre maio e junho de 2013. Aqui, observamos como as manifestações em São Paulo adquiriram características lúdicas e transitórias, e discutimos essas características à luz dos conceitos de ocupação (Vasudevan, 2015: 318), 
ativismo lúdico (Terejina et al., 2013: 385) e lazer civil (Heather, 2002: 215).

A metodologia adotada é a análise de documentos complementada por entrevistas semiestruturadas com dois representantes de uma das organizações à frente das mobilizações, e pela observação dos protestos nos dias 17, 18 e 20 de junho de 2013. A interpretação dos dados buscou identificar as estruturas (Gubrium, 1988: 41) presentes nos fenômenos analisados e a forma como elas são articuladas. $O$ artigo está organizado em 5 partes. A primeira esclarece o referencial teórico. As 3 seguintes são dedicadas a cada uma das etapas apresentadas. A final reúne as conclusões.

\section{Lazer e mobilidade, urbanismo e protestos}

As capacidades do indivíduo de se divertir e deslocar parecem ganhar centralidade na estruturação (Giddens, 1986: 25) da vida social contemporânea, ao se apresentarem como constituintes de desigualdades e hierarquizações. Pertencer ao topo da escala social é deter o que Luís V. Baptista chama de "capital lúdico" (2004: 93), que dá acesso à "possibilidade de vida em festa permanente" (2004: 93) num contexto em que "diversão, prazer e descontração são sinônimos de realização pessoal" (2004: 93). Mobilidade espacial e (consequentemente) social também são "qualidade essencial dos grandes" num mundo em que "os pequenos se caracterizam primordialmente por sua fixidez" (Boltanski e Chiapello, 2009: 370). Assim, a capacidade de deslocar-se, tal como a de divertir-se, constitui-se como um capital social, a que Vincent Kaufmann e outros se referem como motilidade (2004: 750).

Promover e organizar mobilidades é uma função histórica do urbanismo enquanto ferramenta de gestão de diversidades. Da cidade murada, em que o planejamento visou a garantir a boa circulação do poder real por todo um perímetro, passa-se ao de cidade aberta, em que o aumento dos recursos para os deslocamentos serve a promover higiene, comércio e vigilância, e em que o controle passa a ser a administração dessa circulação (Foucault, 2007: 26-35). Essa evolução é acompanhada das mudanças nos tipos-ideais de urbanitas. Ao habitante da Idade Média, seguem-se, após a Revolução Industrial, o utilizador pendular e, em fins de século 20, o utilizador de cidades (Martinotti, 2005: 95). O turista é talvez a forma a mais visível desse último tipo-ideal, num indício de que o urbanita se tornou, além de mais móvel, mais lúdico.

Essa evolução leva a que um principais desafios atuais das cidades e metrópoles seja se tornarem atrativas não apenas como locais de residência e trabalho, mas também de lazer (Pereira et al., 2011: 7). O fomento à mobilidade, então, passa a ser acompanhado do fomento ao lazer. Tal coincidência se materializa nas intervenções urbanísticas que promovem a ocupação dos espaços urbanos de forma transitória e ludicizada (Pereira, 2011: 131), transformando-os no que Luís Vicente Baptista chama de "território lúdico" (2004: 90).

O fato de a onda de manifestações ocorrida a partir de 2010 pelo mundo, na qual os protestos aqui analisados se inserem, se caracterizar pela "presença obstinada" nas ruas (Cohen e Santana, 2015: 104) sugere que os espaços urbanos, mesmo num momento em que a tônica urbanística é objetificá-los para o consumo lúdico, seguem como locus da reivindicação e "ponto onde as diferenças afloram" (Leite, 2008: 51) e que os transforma em espaços públicos efetivos, nos quais é possível observar "instantâneos dos movimentos sociais" da metrópole (Andrade e Baptista, 2015: 143) e a emergência de uma esfera de debate e expressão do dissenso.

Tais manifestações têm colocado em causa tanto a dinâmica cotidiana das cidades - que os movimentos Ocupe (Occupy) tornam mais evidente ao optar por permanências prolongadas que visam a "materialização da [nova] ordem social" demandada pelos ativistas (Vasudevan, 2015: 318) - quanto as políticas urbanísticas. Como observam Yves Cohen e Marco Santana, "o urbano estava em jogo" nas manifestações de Istambul (Turquia), pois ativistas se opunham à construção de um centro comercial em um parque; nas do Rio de Janeiro (Brasil), porque motivadas pelo encarecimento do custo de vida decorrente das melhorias urbanas ancoradas na realização da Copa e das Olimpíadas; e nas de São Paulo, porque tiveram como um de seus alvos o aumento da tarifa de transporte coletivo (2015: 113). Assim, se a atual onda de manifestações é composta de "instanciações diversas de um ciclo internacional de luta contra a desigualdade econômica e social" (Terejina et al., 2013: 318; destaque no original), ao menos em parte elas tomaram a forma de críticas ao urbanismo, inclusive ao que promove e condiciona o consumo lúdico dos espaços urbanos.

A atual utilização desses espaços para fins políticos, por outro lado, também leva a eles formas de ação e discurso, e de experiências e motivações, identificadas com o lazer. Para Benjamín Terejina e outros, as exibições ostensivas de "humor, ironia e paródia" (2013: 385) durante os protestos sugerem a emergência de um "ativismo lúdico" (2013: 385) que tem "prazer, jogo e criatividade no seu centro" (2013: 385). Ou, como colocava Mair Heather há mais de uma década, a emergência de um "lazer civil" (2002: 215), em que os ativistas recorrem ao tempo livre para participar de manifestações e nelas encontram prazer e possibilidade de convivência social (2002: 226), à semelhança do que acontece num momento de divertimento. 


\section{Políticas-alvo}

\section{A Copa}

A Copa - termo com o qual nos referimos ao conjunto Copa do Mundo/Copa das Confederações promove deslocamento. O governo brasileiro divulga que, do total de recursos financeiros investidos em infraestrutura no âmbito da Copa - 84 \% dos quais, públicos -, a maior fatia foi destinada à rubrica mobilidade urbana: US\$3,3 bilhões $^{2}$, ou $32 \%$ do total de US\$10,2 bilhões, foram aplicados em obras e serviços voltados à circulação de veículos e peões. Somados os investimentos em portos e aeroportos chega-se a US\$ 5,9 bilhões (Ministério do Esporte, $\mathrm{s} / \mathrm{d}$ ). Assim, oficialmente, $58 \%$ dos recursos financeiros aplicados na Copa de 2014 foram destinados à constituição de estruturas que ampliam os recursos para a mobilidade. Os estádios receberam $31 \%$.

Tal distribuição serviu a compor a estrutura de interpretação usada pelo governo para justificar o investimento de recursos públicos na Copa. Em artigo intitulado "Os Megaeventos Valem a Pena", publicado 6 meses antes do evento principal, o presidente da Empresa Brasileira de Turismo argumentava que "um de cada três reais investidos pelo governo federal «na Copa» estão sendo usados para melhoria da mobilidade urbana" (Dino, 2013; aspas no original). Tal estrutura também incluiu a ideia de que a Copa promoveria o turismo: os gastos de turistas locais e estrangeiros no país durante os jogos de 2014 atingiriam os mesmos US\$10,9 bilhões da estimativa total de gastos, "superando o volume total de recursos públicos que serão investidos para a realização do evento" (Dino, 2013).

A meta não foi atingida - as despesas de turistas somaram US\$ 3,4 bilhões (Ministério do Turismo, 2015) -, mas o gasto dos internacionais cresceu durante a Copa: nos meses de junho e julho de 2014, quando ocorreram os jogos, essas despesas foram equivalentes a 4 vezes a média histórica iniciada em 1969 e de 1,5 vez a média da década até então (2010-2014). Os jogos da Copa das Confederações apresentam impactos mais tímidos sobre os mesmos indicadores: os gastos de turistas internacionais em junho e julho de 2013 foram entre 2 e 3 vezes superiores à média histórica e inferiores à média da década (Banco Central do Brasil, s/d).

A Copa também promove o lazer por meio da ampliação dos tempos livres. Em todas as cidades-sede da Copa das Confederações com jogos em dias úteis (Belo Horizonte, Recife, Rio de Janeiro e Salvador) houve implementação de ponto facultativo ou feriado (Almeida, 2013; Castro, 2013; Governo Federal, 2013; Prefeitura de Salvador, 2013). Em São Paulo, durante o evento principal, o Poder Público municipal estendeu das $7 \mathrm{~h}$ às $20 \mathrm{~h}$ a restrição à circulação de veículos automotores ${ }^{3}$, que vigora das $7 \mathrm{~h}$ às $10 \mathrm{~h}$ e de $17 \mathrm{~h}$ às $20 \mathrm{~h}$, após o índice de congestionamento na cidade disparar antes de um dos jogos ocorridos na cidade, fenômeno atribuído à saída antecipada de trabalhadores (G1SP, 2014). A operação especial vigorou mesmo em dias em que a seleção brasileira jogou em outras cidades. E, ao longo do evento principal, o expediente de servidores do governo federal foi reduzido em todo o Brasil (Ministério do Planejamento, 2014). Tal reorganização foi fundamental para criar durante os períodos de jogos o anticotidiano (Mendes, 2001/2002: 94) que constitui o momento de lazer.

O anticotidiano também está presente no modelo de gestão adotado para a Copa, que envolve a constituição de "situações de exceção" (Baptista, 2004: 94). No Brasil, houve a criação de um novo regime de contratações públicas, por meio da Lei Federal 12.462 (Presidência da República, 2011) justificado pela necessidade de dar mais agilidade (Celestino, 2012: 171) às obras e serviços necessários à Copa e outros megaeventos. Já a Lei Federal 12.663 (Presidência da República, 2012) concedeu à Federação Internacional de Futebol (FIFA) a autoridade sobre as atividades comerciais realizadas em alguns espaços urbanos de acesso público. Os impactos dessa alteração sobre o trabalho dos comerciantes de rua e sobre a ocupação política dos espaços urbanos fez parte das críticas que foram levadas às ruas em junho de 2013.

\section{A tarifa}

O reajuste das tarifas de transporte coletivo e sua relevância no urbanismo contemporâneo de São Paulo decorrem da estrutura de promoção e organização da mobilidade por meio do sistema de autocarros adotado na cidade. Nela, a capacidade de o indivíduo se deslocar é interpretada como um direito a ser garantido pelo Poder Público na forma de um serviço de transporte coletivo financiado diretamente pelo utilizador por meio de uma tarifa pressionada a ser periodicamente reajustada, embora não exista obrigatoriedade legal. Detalharemos essa estrutura a seguir, mas antes é necessário descrever o sistema de transporte coletivo da cidade.

Os autocarros são o principal meio de transporte coletivo de São Paulo. Respondem por $22 \%$ das viagens realizadas ao destino, ante $10 \%$ do sistema de trilhos (Companhia do Metropolitano de São Paulo, 2012). O serviço é prestado por agentes privados, remunerados pelo Poder Público. O financiamento é feito majoritariamente pelo utilizador: em dezembro de 2014, a tarifa, única para toda a cidade, foi de US\$1,13, equivalente a $63 \%$ do US\$ 1,80 necessário para que o custo global do sistema, incluindo descontos e gratuidades, fosse arcado exclusivamente pelo utilizador. Os $37 \%$ restantes são oriundos do caixa comum da Prefeitura, que 
exerce o Poder Executivo municipal (São Paulo Transportes, s/d).

Tal estrutura de ação materializa a legislação que rege o sistema. Na Constituição Federal brasileira de 1988, o transporte coletivo é descrito como um serviço público de "caráter essencial" a ser prestado pelo Poder Público municipal, diretamente ou por meio de concessão ou permissão (Assembleia Nacional Constituinte, 1988). A Lei Orgânica do Município de São Paulo, espécie de constituição municipal, apresenta "a locomoção através de transporte coletivo adequado, mediante tarifa acessível ao usuário" como um dos direitos "inerentes às condições de vida na cidade", a serem garantidos pelo poder municipal (Assembleia Constituinte do Município de São Paulo, 1990). A Lei Municipal 13.241, que organiza o transporte coletivo, estabelece entretanto que tal tarifa deve "suportar" os custos do sistema, inclusive a remuneração dos concessionários e permissionários, que "deverá sofrer reajuste, periodicamente" (Prefeitura de São Paulo, 2001a). E, embora os decretos 42.736 (Prefeitura de São Paulo, 2002) e 53.887 (Prefeitura de São Paulo, 2013a), regulamentadores da lei, abram outras possibilidades de financiamento - inclusive, a partir de 2013, recursos do caixa comum da Prefeitura que, não obstante, já vinham sendo utilizados -, a principal fonte de recursos é a tarifa.

É desse atrelamento a um custo periodicamente revisto que decorre o reajuste de tarifa alvo dos protestos de 2013. E, como tais reajustes não estão previstos expressamente na legislação, o Poder Público tem certa liberdade para escolher os índices e momentos de aplicação, e pode recorrer ao caixa da Prefeitura para compensar eventuais desequilíbrios. Com isso, desde 2001, quando teve início o modelo legal vigente à época dos protestos, a tarifa foi aumentada 7 vezes, nunca em ano de eleição municipal (foram 4 no período) e em meses variados, mas quase sempre (4 das 7 oportunidades) em janeiro (Prefeitura de São Paulo, 2001b; Prefeitura de São Paulo, 2003; Prefeitura de São Paulo, 2005; Prefeitura de São Paulo, 2006; Prefeitura de São Paulo, 2010; Prefeitura de São Paulo, 2011; Prefeitura de São Paulo, 2013b; e Prefeitura de São Paulo, 2013c).

Em 2013, o reajuste foi aplicado em junho, diferentemente do que havia ocorrido nos 2 anos anteriores, em decorrência de um acordo entre o prefeito de São Paulo e o governo federal para diminuir o impacto sobre o indicador de inflação no início do ano (Cardoso, 2013). A decisão empurrou para o mês da realização da Copa das Confederações o momento em que o conflito de interesses entre utilizador e operador de sistema de transporte coletivo - um conflito permanente nos modelos de financiamento via tarifa (Mendonça, 1997: 23) se torna mais evidente. Para além de a fixação de uma nova tarifa atrair a atenção do indivíduo no ato mesmo de pagá-la, os critérios para a fixação dessa nova tarifa devem por obrigação legal ser divulgados amplamente, obriga a Lei Orgânica do Município, e é comum que o reajuste seja objeto de debate público. Em 2013, isso aconteceu em junho, período em que esse espaço público já era ocupado por outro alvo de crítica - a realização da Copa.

Em suma, os protestos de junho de 2013 levaram ao espaço público críticas a duas políticas urbanísticas que estavam então em evidência. De um lado, a Copa, que promove e condiciona a utilização lúdica das cidades, numa materialização do urbanismo voltado à produção de territórios lúdicos, inclusive no que diz respeito à criação da excepcionalidade gestionária. De outro, a cobrança e o reajuste da tarifa de transporte coletivo público, que, ao materializar a função histórica do urbanismo de fomentar e organizar mobilidades - e a justificação da Copa com investimentos em "mobilidade urbana" é indicadora dessa centralidade -, condiciona capacidades de deslocamento do indivíduo ao seu capital financeiro, e permite que as desigualdades econômicas se traduzam em de motilidade.

\section{Crítica}

\section{À Copa}

Passamos à análise de duas organizações que convocaram protestos para junho de 2013. Uma delas foi escolhida por ter surgido com o objetivo específico de fazer crítica à realização da Copa. A outra, pelo protagonismo que adquiriu nas manifestações. Ambas partilham de similaridades na composição, nas formas de ação e na pauta de reivindicações.

A crítica à Copa levou à constituição de Comitês Populares da Copa em cada uma das 12 cidades-sede do evento, reunidos na Articulação Nacional dos Comitês Populares da Copa (Ancop). A Ancop e o Comitê Popular da Copa de São Paulo, aos quais nos referiremos como Movimento da Copa, emergiram de sessões de debate sobre o impacto de megaeventos. Entre os integrantes do movimento há representantes de Organizações Não Governamentais, associações, universidades, movimentos sociais de moradia, grupos de teatro, órgãos públicos e pessoas sem filiação declarada a outras instituições. A composição não é estática, com adensamento maior em época de manifestações de rua e menor no período de férias escolares.

O movimento tem 4 estruturas de ação principais: realização de protestos de rua, na forma de passeatas, peças teatrais e jogos de futebol; organização de reuniões públicas, de conversas informais a seminários e debates combinados com jogos de futebol (os debates-bola); produção e disseminação 
de informações sobre os alegados impactos da Copa; e diálogos com o Poder Público, desvalorizados por serem considerados de baixa resolutividade.

O objetivo declarado pelo Movimento da Copa é evitar violações de direitos perpetradas em razão da realização da Copa e das Olimpíadas de 2016. O sumário dessas alegadas violações, publicado em 2012 pela Ancop, apresenta 7 áreas, resumidas abaixo. Além delas, há no documento e surgem nas entrevistas críticas a) à destruição de equipamentos de lazer em razão das obras da Copa; b) ao aumento do preço dos ingressos nos estádios; c) à exploração sexual; d) ao privilégio do transporte privado em detrimento do público em obras de mobilidade. de trânsito e transporte que, orientadas pelo objetivo de valorizar os imóveis de uma determinada região e privilegiadoras do transporte privado, não serviriam a garantir igualdade de acessibilidade ao território urbano. Tal reivindicação do direito à igualdade de condições de mobilidade, que é apresentada como "condição mesma da vida na cidade" (Ancop, 2012: 32), é uma das interfaces do Movimento da Copa com o Movimento Passe Livre, protagonista dos protestos de junho e analisado a seguir.

\section{À tarifa}

O Movimento Passe Livre aponta como sua origem os protestos contra a cobrança de tarifas

Quadro $1 \triangleright$ Resumo das críticas e reivindicações da Ancop

\begin{tabular}{ll}
\multicolumn{1}{c}{ Áreas } & \multicolumn{1}{c}{ Críticas/reivindicações } \\
Moradia & Remoções forçadas em decorrência das obras (viárias e de lazer) e gentrificação \\
Trabalho & $\begin{array}{l}\text { Más condições de trabalho nos estádios; restrições ao desempenho da } \\
\text { atividade profissional (comércio formal e informal, inclusive ambulante), } \\
\text { sobretudo nos arredores dos estádios }\end{array}$
\end{tabular}

Informação, participação e representação popular
Negativa de prestação de informações e de participação dos indivíduos nos processos decisórios; criação de estrutura de governo excecional para o evento

Meio ambiente
públicosso a serviços e bens

Mobilidade

Segurança pública

Impactos das intervenções no meio ambiente natural

Carência de investimentos em saúde, educação, saneamento, energia elétrica e comunicações, ao mesmo tempo em que se investe nas estruturas físicas para a Copa

Obras viárias inadequadas por beneficiarem territórios/habitantes já atendidos por transporte público em detrimento de outros; por causarem remoções de moradores; e por fomentarem a valorização imobiliária

Impedimento à ocupação dos espaços públicos para protestar; criminalização de populações carentes; favorecimento da valorização imobiliária
Tais críticas revelam que a promoção de lazer e mobilidade por meio de megaeventos é interpretada como motivadora de violações de outros direitos: as obras realizadas nos estádios e em outros equipamentos lúdicos, além das de trânsito e transporte, são acusadas de forçarem o desalojamento de habitantes de moradias de baixa renda; a gestão do espaço urbano em razão da Copa é denunciada por impedir a permanência de comerciantes de rua, sem-abrigo e manifestantes em determinados locais; e os investimentos em equipamentos lúdicos são criticados por drenarem recursos que poderiam ser aplicados em áreas como saúde e educação.

Numa segunda estrutura, lazer e mobilidade são interpretados como direitos violados pelos megaeventos em razão do encarecimento do preço dos ingressos para os estádios de futebol; da demolição de equipamentos de lazer; e da realização de obras nos autocarros em Salvador (Bahia) de 2003. A fundação oficial ocorreu em 2005 (Movimento Passe Livre, 2013).

À semelhança do Movimento da Copa, o Passe Livre se organiza numa forma rizomática que englobava, na época, 16 grupos independentes distribuídos pelo país (Movimento Passe Livre, s/da). Integram ou integraram esses coletivos estudantes, trabaIhadores, membros de associações de moradores e de sindicatos, professores e "população em geral" (Movimento Passe Livre, s/da), perfil semelhante ao do Movimento da Copa.

O Passe Livre também coincide com esse movimento nas estruturas de ação: produção e disseminação de informações e análises sobre sua pauta de reivindicações; realização de manifestações de rua (perturbação do trânsito, não-pagamento das tarifas de transporte público, e o que é cha- 
mado de intervenções lúdicas ${ }^{4}$ ); e diálogo com o Poder Público (criação de leis de iniciativa popular como a que estabeleceu o passe livre estudantil em Florianópolis, capital de Santa Catarina). A crítica à baixa resolutividade do diálogo do Poder Público é feita por meio da criação de linhas de transporte público à revelia de regulamentação.

A pauta mestra do Passe Livre é estabelecer a gratuidade do transporte público e a gestão exclusivamente pública desse serviço, descritas como parte de um processo maior de constituição de "uma outra organização do transporte, da cidade e de toda a sociedade" (Movimento Passe Livre, 2013: 17) uma vez que o transporte é entendido como "transversal a diversas outras pautas urbanas", por garantir "o acesso aos demais serviços públicos" (Movimento Passe Livre, 2013: 16).

Assim, existe no discurso do Passe Livre uma estrutura de interpretação que coloca a mobilidade como um direito violado, e cuja violação resulta em prejuízo a outros direitos do cidadão da metrópole, à semelhança do que ocorre com o Movimento da Copa. O movimento antitarifário também critica a realização de megaeventos ${ }^{5}$, com o argumento de que os recursos aí investidos deveriam ser aplicados em saúde, educação, moradia e transporte.

A essa série de coincidências de estruturas de ação e de interpretação, soma-se a que tornou junho de 2013 um contexto privilegiado para a expressão das pautas de reivindicações de ambos os movimentos. Para o Passe Livre, tratava-se do mês em que entrou em vigor o reajuste das tarifas de transporte coletivo. Para o Movimento da Copa, segundo um de seus integrantes, a Copa das Confederações daria visibilidade à crítica à Copa pela concentração de público e imprensa provocada pelos jogos, e as alterações no cotidiano em razão do evento, como as restrições à permanência nos espaços urbanos, estariam em pleno vigor, tornando-as mais evidentes.

Na presente etapa, elencamos algumas características das duas organizações que convocaram os protestos de junho de 2013 que as aproximam entre si e, acreditamos, permite-nos colocá-las na perspectiva dos recentes movimentos reivindicatórios internacionais. Do ponto de vista das estruturas de ação, ressaltamos o recurso à ocupação de espaços urbanos e a atividades esportivas ou criativas e, do ponto de vista organizacional, a forma rizomática condizente com a diluição da figura do líder, traço comum a movimentos surgidos a partir de 2010 (Cohen e Santana, 2015: 107). Em relação às pautas, a crítica à desigualdade social que embasa os movimentos reivindicatórios se traduz, em São Paulo, na forma de um ataque a alegados impactos negativos da Copa - próxima da acusação de "esvaziamento ou privatização dos serviços públicos" (2013: 386), que segundo Terejina e outros motivou os protestos em outras partes do mundo - e na demanda por uma distribuição mais igualitária dos capitais lúdico e, especialmente, de mobilidade.

\section{A rua}

Nesta seção, o objetivo é demonstrar como mobilidade e lazer constituíram as estruturas dos protestos nas ruas. Faremos isso por meio da análise de seus locais, horários e ações.

Foram levados em consideração 14 protestos ocorridos de 19 de maio a 30 de junho de 2013 em São Paulo (Comitê Popular da Copa de São Paulo, 2013; Movimento Passe Livre de São Paulo, 2013a; Movimento Passe Livre de São Paulo, 2013b; Movimento Passe Livre de São Paulo, 2013c; Movimento Passe Livre de São Paulo, 2013d; Movimento Passe Livre de São Paulo, 2013e; Movimento Passe Livre de São Paulo, 2013f; Movimento Passe Livre de São Paulo, 2013g; Movimento Passe Livre de São Paulo, 2013h; Movimento Passe Livre de São Paulo, 2013i; Movimento Passe Livre de São Paulo, 2013j; e Movimento Passe Livre de São Paulo, 2013k). O período compreende 2 dos 3 eventos "Copa pra Quem" e uma manifestação em forma de partida de futebol convocados pelo Movimento da Copa; e 7 atos contra o aumento da tarifa realizados pelo Passe Livre. Observamos presencialmente três protestos: os de 17 e 18 de junho, que antecederam imediatamente a revogação do aumento, e o de 20 de junho, que a sucedeu. A escolha foi contingente. O autor, jornalista, foi escalado excepcionalmente para a cobertura a partir da primeira manifestação observada, como parte de um reforço da equipe do veículo de comunicação demandado pelo crescimento em tamanho e relevância da mobilização.

Os locais e horários dos protestos revelam uma estrutura de ação em que a perturbação da mobilidade quotidiana é um objetivo, e não mera consequência. Sete foram marcados para horários e locais em que vigora o rodízio. Outros 4, marcados para fora da zona de rodízio, ocorreram nas proximidades de terminais de autocarros ou de metropolitano no início da manhã, quando o fluxo de passageiros é elevado. Um quinto foi marcado para um terminal de autocarros dentro da zona de rodízio.

A interrupção deliberada da circulação de avenidas $^{6}$ reforça essa conclusão. Em 20 de junho, um grupo destacou-se do protesto que ocorria na Avenida Paulista com o intuito de paralisar a 23 de Maio, principal ligação entre as zonas norte e sul da cidade. Além de impedir a passagem, alguns pediam que os motoristas deixassem os carros parados na via. Em 3 de junho, barricadas foram montadas para fechar a Estrada do M'Boi Mirim, uma das principais vias da zona sul.

A mobilidade também se expressa na forma móvel adotada na rua: em vez de ocupações permanentes, os protestos tomaram quase sempre 
forma de passeatas. Assim, a Avenida Paulista, por onde passaram boa parte das manifestações de São Paulo, diferencia-se da Praça do Sol madrilenha e da Liberty Financial Square nova-iorquina de 2011, também espaços de uma expressão política massiva no espaço urbano, por ter sido palco de manifestações intermitentes, e não perenes: em São Paulo, os protestos terminavam horas depois de iniciados, não raro em locais diferentes dos de início, para tornarem a ocorrer em um segundo momento 7 .

Tal rotina intermitente contribuiu para constituir o caráter lúdico das manifestações, que tiveram início marcado sobretudo para o fim dos dias úteis (a partir das $16 \mathrm{~h}$ em 7 das 13 oportunidades) e, em 2 ocasiões, para domingos à tarde. Com isso, foi comum que os protestos ocorressem em períodos de tempos livres. Os locais escolhidos reforçam tal caráter. Um dos protestos de domingo foi marcado para a Praça Júlio Prestes, ponto turístico da cidade, que naquele dia abrigava eventos da Virada Cultural, projeto de lazer de grande porte da Prefeitura. $\mathrm{O}$ outro protesto de domingo ocorreu no Vale do Anhangabaú, área pedonal usada para concertos e outras ocupações de lazer no centro da cidade. O perímetro da Avenida Paulista, por onde passaram ao menos 8 dos 14 protestos, reunia 2 parques, 3 cinemas, 11 centros culturais, 2 das mais relevantes âncoras de lazer da cidade - o Museu de Arte de São Paulo e Casa das Rosas - e 1 clube, além de lojas de comércio e serviços que se prestam ao passear na forma de olhar as montras ${ }^{8}$.

O ambiente festivo também foi constituído pelo recurso a ações artísticas. Em 4 dos 14 protestos houve a participação de bandas de fanfarra e, em 1 , a realização de uma peça de teatro. Na manifestação de 20 de junho - após a revogação do aumento - um grupo de participantes parou para apreciar o concerto de uma banda de artistas de rua na Avenida Paulista. Noutra parte da via, ativistas dançavam e gritavam "vem pra rua contra o governo" ao ritmo samba tocado por percussionistas. Além disso, foi comum observar em diversos dias a oferta e consumo de bebida alcoólica.

Nos cartazes e na indumentária, o uso de ironia e humor - indiciários do ativismo lúdico - era comum. Um ativista, em 18 de junho, vestiu-se com a roupa do personagem Super-Homem. Outros pintavam a cara como palhaços de circo. A frase "não quero o troco em balas", referência à prática comum no país de devolver com doces o valor pago a maior numa compra, foi exibida por uma manifestante para criticar a utilização de balas (projéteis) de borracha pela polícia. Após a prisão de um jornalista por carregar vinagre (que minimiza o efeito do gás lacrimogênio), a frase "Liberté, Fraternité, Égalité e Vinagré" foi colada a uma parede num dos locais de manifestação.
O caráter lúdico foi identificado pelos participantes - em 17 de junho, uma manifestante carregava o cartaz "82 anos [de idade]; não vim para brincar, vim manifestar" - e motivou críticas. Em 20 de junho, cartazes com os dizeres "\#protestoconsciente" e "Aqui não é balada" foram exibidos por 2 ativistas que caminhavam em conjunto pela Avenida Paulista. A última frase permaneceu grafitada em um muro junto a via por meses.

Assim, a utilização dos espaços urbanos nos protestos de junho teve um caráter móvel e lúdico. A primeira característica se expressa na permanência intermitente no terreno, em oposição às ocupações mais permanentes observadas em outras partes do mundo. Tal rotina, aliada ao fato de que as manifestações ocorreram sobretudo em horários de tempo livre e em territórios ludicizados pela gestão urbanística, contribuíram para a constituição do caráter lúdico, que foi reforçado pelo recurso a formas de expressão artísticas, irônicas e humorísticas, e ao desempenho de atividades relacionadas a festas, como dança, fruição de música e o consumo de bebida alcoólica. Essa segunda característica evidencia a expressão do ativismo lúdico identificado nos movimentos ocorridos fora do país.

\section{Conclusão}

A análise aqui empreendida demonstra que, embora tenham se configurado como o rompimento da ordem cotidiana da história recente de São Paulo, os protestos de junho de 2013 trocaram uma ocupação lúdica e transitória dos espaços urbanos por outra radicalmente diferente, mas também lúdica e transitória. Tal continuidade indica que a mobilidade e o lazer são centrais não só ao planejamento urbano e à vivência por ele prevista para os espaços urbanos, como também para a ressignificação de tais espaços nos momentos de expressão do dissenso - na transformação do espaço urbano em espaço público - numa materialização móvel do ativismo lúdico que emerge no atual ciclo de mobilizações.

Além disso, nossa análise demonstra que, também em São Paulo como em outros exemplares desse ciclo, a questão urbana e a desigualdade social estiveram no alvo dos protestos, na forma de críticas a políticas que interferem, por meio da produção e gestão da cidade, na constituição, na formatação e na distribuição dos potenciais de deslocamento e diversão dos urbanitas. Em outras palavras, em dois capitais - o lúdico e o de mobilidade - fundamentais à hierarquização social contemporânea.

\section{Notas}

Artigo realizado como parte do trabalho de colaboração do autor no âmbito do Grupo de Investigação 3 - Mudanças Ambientais, Território e Desenvolvimento do CICS.Nova. 
2 R\$ 8,7 bilhões no câmbio de 31 de dezembro de 2014, em que US\$ 1 equivalia a R\$2,6556.

3 O programa, conhecido como rodízio e criado em 1997 pela lei 12.490 (Prefeitura de São Paulo, 1997), proíbe em cada dia da semana a circulação, nos horários citados, de veículos com placas terminadas em um ou outro algarismo: às segundas-feiras não circulam os de final 1 e 2 e assim sucessivamente.

4 Na versão da Carta de Princípios vigente à época dos protestos.

5 Um texto em comemoração pela derrota da candidatura paulistana a sede da Exposição Mundial de 2020 (Movimento Passe Livre de São Paulo, 2013a) é concluído com o lema "Por Uma Vida sem Catracas" acrescido da frase "e sem Megaeventos".

6 Dentre elas, Paulista, 23 de Maio, Nações Unidas, ConsoIação, Chucri Zaidan, Roberto Marinho, Estrada do M’Boi Mirim.

7 Mas não exclusiva: um acampamento permaneceu junto à Assembleia Legislativa do Estado de São Paulo ao menos entre agosto de 2013 e fevereiro de 2014.

8 Fora dos dias úteis, parte das faixas de rodagem de trânsito era, à época, convertida em ciclofaixa de lazer.

\section{Referências bibliográficas}

ANDRADE, L. T. de e L. V. Baptista (2015), "Espaços públicos: interações, apropriações e conflitos", Sociologia, 39, pp. 129-146.

BAPTISTA, L. V. (2004), "Territórios lúdicos (e o que torna lúdico um território): Ensaiando um ponto de partida", Actas dos ateliers do $V$ Congresso Português de Sociologia, pp. 90-96.

BOLTANSKI, L. e È. Chiapello (2009), O novo espírito do capitalismo, São Paulo, Martins Fontes.

CELESTINO, F. C. R. (2012), "Regime Diferenciado de Contratação: breves comentários à exceção que virou tendência", Revista Controle, 10 (2), pp. 170-201.

COHEN, Y. e M. Santana (2015), "Du Brésil au monde et retour: mouvements sociaux localisés et en résonance", Brésil(s), 7, pp. 103-122.

FOUCAULT, M. (2007), Security, territory, population, Hound Mills, Nova Iorque, Palgrave MacMillan.

GIDDENS, A. (1986), The constitution of society, Cambridge, Polity Press.

GUBRIUM, J. (1988), Analysing field reality, Beverly Hills, Londres, Sage.

HEATHER, M. (2002), "Civil leisure? Exploring the relationship between leisure, activism and social change", Leisure/Loisir, 27 (3-4), pp. 213-237.

KAUFMANN, V. et al. (2004), "Motility: mobility as a capital", International Journal of Urban and Regional Research, 28 (4), pp. 745-756.

LEITE, R. P. (2008), "Localizando o espaço público: gentrification e cultura urbana", Revista Crítica de Ciências Sociais, 83, pp. 35-54.
MARTINOTTI, G. (2005), "Social morphology and governance in the new metropolis", in Y. Kazepov (ed.), Cities of Europe, Malden, Oxford, Victoria, Blackwell Publishing, pp. 90-109.

MENDES, L. (2001/2002), "O lazer e o recreio no Parque da Nações: o consumo, o lúdico e o estético na produção da cidade pós-moderna", Inforgeo, $17 / 18$, pp. 81-108.

MENDONÇA, A. L. M. de (1997), Gestão pública, regulamentação e flexibilidade de planejamento: a experiência de "municipalização" do transporte coletivo em São Paulo (1989-1992), Dissertação de mestrado em Administração, São Paulo, EEASP-FGV

Movimento Passe Livre (2013), "Não começou em Salvador, não vai terminar em São Paulo", in Cidades Rebeldes. Passe livre e as manifestações que tomaram as ruas do Brasil, E. Maricato et al. (eds.), São Paulo, Boitempo, pp. 13-18.

PEREIRA, P. et al. (2011), "Editorial", Forum Sociológico, 21, pp. 7-9.

PEREIRA, V. S. (2011), Para o "cidadão em abstracto": a produção de espaços públicos na cidade reurbanizada, Dissertação de mestrado em Sociologia, Lisboa, FCSH-UNL.

TEREJINA, B. et al. (2013), "From indignation to occupation: A new wave of global mobilization", Current Sociology, 61 (4), pp. 377-392.

VASUDEVAN, A. (2015), "The autonomous city: Towards a critical geography of occupation", Progress in Human Geography, 39 (3), pp. 316-337.

Outras

Articulação Nacional dos Comitês Populares da Copa (2012), "Megaeventos e violações de direitos humanos no Brasil", http://bit.ly/1C8KmZG, 5/6/15.

Assembleia Constituinte do Município de São Paulo (1990), "Lei Orgânica do Município".

Assembleia Nacional Constituinte (1988), "Constituição da República Federativa do Brasil".

ALMEIDA, P. I. (2013), "Mesmo com pior público, BH terá ponto facultativo para Taiti x Nigéria", UOL, http://bit.ly/1LHxQDg,5/6/15.

Banco Central do Brasil (s/d), "Viagens anuais - total", http://bit.ly/1vXbWpE, 5/6/15.

CARDOSO, D. (2013), "Haddad afirma que vai manter tarifa de ônibus até junho", O Estado de São Paulo, http://bit.ly/1eiz6yC, 5/6/15.

CASTRO, B. de (2013), "Prefeitura anuncia feriado em dois dias de jogos da Copa das Confederações", O Povo, http://bit.ly/1LUr2PK, 5/6/15.

Comitê Popular da Copa de São Paulo (2013), "Agenda de ações para junho: ato Copa para quem?", http:// bit.ly/1dwPEC6, 5/6/15.

Companhia do Metropolitano de São Paulo (2012), "Pesquisa de Mobilidade Urbana", http://bit. ly/1GXwJ1J, 11/11/15.

DINO, F. (2013), "Os megaeventos valem a pena", http://bit.ly/1JwtOgs, 4/6/15. 
G1SP (2014), "SP trava com 302 km de filas em pico antecipado por jogo do Brasil", G1, http://glo. bo/1JwtRch, 5/6/15.

Governo Federal (2013), "Rio de Janeiro tem ponto facultativo e feriado escolar nesta quinta-feira" , http://bit.ly/1U7pJCB, 5/6/15.

Ministério do Esporte (s/d), "Matriz de responsabilidades consolidada", http://bit.ly/1f0ou8m, 4/6/15.

Ministério do Planejamento, Orçamento e Gestão (2014), "Portaria 113/14".

Ministério do Turismo (s/d), "Reposta ao pedido de acesso à informação de protocolo 72550000044201517", comunicação pessoal, 23/3/15.

Movimento Passe Livre (s/da), "Site oficial", http://bit. ly/1gaRdrm, 5/6/15.

Movimento Passe Livre (s/db), "Site oficial", http://bit. ly/1gaRdrm, 3/5/14.

Movimento Passe Livre de São Paulo (2013a), "Não vai ter Expo 2020", http://bit.ly/1NvbDq5, 5/6/15.

Movimento Passe Livre de São Paulo (2013b), "Protestos na M'Boi Mirim no primeiro dia do aumento", http://bit.ly/1gaRivg, 5/6/15.

Movimento Passe Livre de São Paulo (2013c), "Luta contra o aumento: calendário de ações da semana", http://bit.ly/1HwFijN, 5/6/15.

Movimento Passe Livre de São Paulo (2013d), "Intervenção contra o aumento na Virada Cultural", http://bit.ly/1Ksn8QR, 5/6/15.

Movimento Passe Livre de São Paulo (2013e), "Novo ato contra o aumento na sexta", http://bit. ly/1Q8QsOY, 5/6/15.

Movimento Passe Livre de São Paulo (2013f), "Ato Copa para quem na final", http://bit.ly/1HwFhwg, 5/6/15.

Movimento Passe Livre de São Paulo (2013g), "Sobre o ato de 20/6", http://bit.ly/1CJ088f, 5/6/15.
Movimento Passe Livre de São Paulo (2013h), "Convocatória grande ato contra o aumento", http://bit. ly/1FQxzFW, 5/6/15.

Movimento Passe Livre de São Paulo (2013i), "Intervenção na Ponte Estaiada e na Câmara Municipal", http://bit.ly/1IN6e90, 5/6/15.

Movimento Passe Livre de São Paulo (2013j), "Nota pública sobre os atos do dia 17/6", http://bit. ly/1C8L5dc. Consulta em 5/6/15.

Movimento Passe Livre de São Paulo (2013k), "A periferia de São Paulo vai continuar parando", http:// bit.ly/1NwuVee, 5/6/15.

Presidência da República (2011), "Lei 12.462/11".

Presidência da República (2012), "Lei 12.663/12".

Prefeitura de Salvador (2013), "Prefeitura decreta feriado municipal na quinta (20) e no sábado (22)", http:// bit.ly/1GYOsCk, 5/6/15.

Prefeitura de São Paulo (1997), "Lei 12.490/97".

Prefeitura de São Paulo (2001a), "Lei 13.241/01".

Prefeitura de São Paulo (2001b), "Decreto 40.655/01".

Prefeitura de São Paulo (2002), "Decreto 42.736/02".

Prefeitura de São Paulo (2003), "Decreto 42.782/03".

Prefeitura de São Paulo (2005), "Decreto 45.749/05".

Prefeitura de São Paulo (2006), "Decreto 47.919/06".

Prefeitura de São Paulo (2010), "Decreto 51.134/10".

Prefeitura de São Paulo (2011), "Decreto 52.041/11".

Prefeitura de São Paulo (2013a), "Decreto 53.887/13".

Prefeitura de São Paulo (2013b), "Decreto 53.935/13".

Prefeitura de São Paulo (2013c), "Decreto 54.016/13".

São Paulo Transportes (s/d), "Relatório planilha de custos tarifa jan2015 vfinal", http://bit.ly/1R3YtpD, $5 / 6 / 15$.

Vitor Sorano Pereira (vspereira@fcsh.unl.pt). Universidade Nova de Lisboa, Centro Interdisciplinar de Ciências Sociais (CICS-NOVA). Av. de Berna, 26 C, 1069-061 Lisboa, Portugal. 